\title{
Local recurrence of myxofibrosarcoma is associated with increase in tumour grade and cytogenetic aberrations, suggesting a multistep tumour progression model
}

\author{
Stefan M Willems ${ }^{1}$, Maria Debiec-Rychter ${ }^{2}$, Károly Szuhai ${ }^{1,3}$, Pancras CW Hogendoorn ${ }^{1}$ \\ and Raphäel Sciot ${ }^{4}$ \\ ${ }^{1}$ Department of Pathology, Leiden University Medical Center, Leiden, The Netherlands; ${ }^{2}$ Department of \\ Human Genetics, University Hospitals, Catholic University of Leuven, Leuven, Belgium; ${ }^{3}$ Department of \\ Molecular Cell Biology, Leiden University Medical Center, Leiden, The Netherlands and ${ }^{4}$ Department of \\ Morphology and Molecular Pathology, University Hospitals, Catholic University of Leuven, Leuven, Belgium
}

\begin{abstract}
Myxofibrosarcoma is one of the most frequent soft tissue tumours in elderly patients, mostly arising in the extremities. Grade I lesions are only locally aggressive whereas grade II and grade III lesions have metastatic potential. The differential diagnosis contains several other (benign) myxoid soft tissue tumours. A number of sarcomas are characterised by specific cytogenetic aberrations, giving not only insight in their biological pathways; they also serve as molecular markers in difficult diagnoses. Cytogenetic data on myxofibrosarcoma are scarce with only few isolated cases described in the literature. No specific chromosomal aberrations have been detected so far. Moreover, molecular pathways in tumorigenesis and progression of myxofibrosarcoma are barely understood. We studied the clinicopathologic data and karyotypes of $\mathbf{3 2}$ myxofibrosarcomas using conventional banding and multicolour COmbined Binary RAtio labelling fluorescence in situ hybridisation technique. We included eight grade I, eight grade II and 16 grade III lesions. In all, 22 were primary tumours, nine were local recurrences and one a lymph node metastasis. The myxofibrosarcomas showed equal sex distribution, were mostly located at the extremities with two thirds deep-seated and had an average age of occurrence of 66 years. We found normal karyotypes in eight cases and clonal beside nonclonal aberrations in 22 cases. Complex cytogenetic anomalies were found in all grades. However, no tumour-specific chromosomal abnormalities could be withdrawn. Local recurrences showed increase in grade compared to their primary lesions. Interestingly, these recurrences showed more complex cytogenetic aberrations. Increase in grade seems to parallel increase in cytogenetic aberrations and malignant potential. Since the chromosomal aberrations found were not tumour type specific, they seem to be rather the result of secondary events in tumour progression and tumour genetic instability. Based on these findings, we suggest that tumorigenesis of myxofibrosarcoma is mainly a multistep genetic process, probably ruled by genetic instability caused by targeted checkpoint genes.
\end{abstract}

Modern Pathology (2006) 19, 407-416. doi:10.1038/modpathol.3800550; published online 13 January 2006

Keywords: cytogenetics; soft tissue tumours; myxofibrosarcoma; myxoid malignant fibrous histiocytoma; ring chromosomes; imbalances

Myxofibrosarcoma, formerly also known as the myxoid variant of malignant fibrous histiocytoma, is one of the most frequent sarcomas in elderly patients with the majority arising in the extremities,

Correspondence: Dr SM Willems, MD, Department of Pathology, Leiden University Medical Center, PO Box 9600, L-1-Q, 2300 RC Leiden, The Netherlands.

E-mail: S.M.Willems@lumc.nl

Received 28 September 2005; revised and accepted 8 December 2005; published online 13 January 2006 clinically most often presenting as a slowly increasing mass. ${ }^{1-3}$ Histologically, myxofibrosarcomas show a wide range from hypocellular grade I tumours with oval to spindle form cells in a myxoid stroma, to hypercellular grade III lesions of solid sheets with pleomorphic nuclei. ${ }^{4}$ According to the French Fédération Nationale des Centres de Lutte Contre le Cancer (FNLCC) grading system, three histological grades are recognised, that is, grade I, II and III. ${ }^{5}$ Metastatic potential is closely related to tumour grade, with a preference for lung, bone and 
lymph nodes. Importantly, increasing grade is seen in subsequent recurrences. ${ }^{4}$ Cytogenetic data on myxofibrosarcoma are scarce with 30 isolated cases described in the literature. Most often, karyotypes are very complex, including ring chromosomes, deletions, translocations and double minutes. Here, we present the clinicopathologic data and karyotypes of 32 cases of myxofibrosarcoma and discuss our findings in the light of tumour grade and clinical behaviour.

\section{Materials and methods}

\section{Patient Data}

Thirty-two cases of myxofibrosarcoma were identified on which cytogenetic data were available and collected retrospectively from the files of the Pathology Departments of the University Hospitals of Leuven and Leiden University Medical Center. Patient and tumour characteristics were described in Table 1. In each case, $4 \mu \mathrm{m}$-thick sections of formalin-fixed, paraffin-embedded material were stained with haematoxylin and eosin (H\&E). Slides were revised and classified according to the 2002

Table 1 Patient and tumour characteristics

\begin{tabular}{ccclll}
\hline Case & $P / R / M^{\mathrm{a}}$ & Sex & Age & Site & Grade \\
& & & & & \\
1 & $\mathrm{P}$ & $\mathrm{M}$ & 61 & In left musculus gracilis & $\mathrm{I}$ \\
2 & $\mathrm{P}$ & $\mathrm{M}$ & 46 & In left musculus deltoideus & I \\
3 & $\mathrm{P}$ & $\mathrm{F}$ & 55 & In left vastus lateralis & I \\
4 & $\mathrm{P}$ & $\mathrm{M}$ & 81 & Right upper arm (superficial) & I \\
5 & $\mathrm{P}$ & $\mathrm{F}$ & 64 & In right musculus quadriceps & I \\
6 & $\mathrm{P}$ & $\mathrm{F}$ & 64 & In right musculus quadriceps & I \\
7 & $\mathrm{P}$ & $\mathrm{M}$ & 60 & Left thigh (superficial) & I \\
8 & $\mathrm{P}$ & $\mathrm{F}$ & 49 & In left musculus gluteus & I \\
9 & $\mathrm{P}$ & $\mathrm{F}$ & 79 & Forearm (superficial) & II \\
10 & $\mathrm{P}$ & $\mathrm{M}$ & 55 & In musculus biceps femoris & II \\
11 & $\mathrm{P}$ & $\mathrm{M}$ & 69 & Right lower leg (intramuscular) & II \\
12 & $\mathrm{R}$ & $\mathrm{M}$ & 81 & Right upper arm (superficial) & II \\
13 & $\mathrm{P}$ & $\mathrm{M}$ & 69 & In right thoracic muscle & II \\
14 & $\mathrm{R}$ & $\mathrm{F}$ & 63 & Left thigh (superficial) & II \\
15 & $\mathrm{R}$ & $\mathrm{F}$ & 63 & Left thigh (superficial) & II \\
16 & $\mathrm{P}$ & $\mathrm{F}$ & 68 & Right elbow (superficial) & II \\
17 & $\mathrm{P}$ & $\mathrm{M}$ & 77 & Right thigh (superficial) & III \\
18 & $\mathrm{P}$ & $\mathrm{F}$ & 70 & Pretibial (superficial) & III \\
19 & $\mathrm{R}$ & $\mathrm{M}$ & 61 & In left musculus gracilis & III \\
20 & $\mathrm{P}$ & $\mathrm{M}$ & 65 & Right lower leg & III \\
21 & $\mathrm{R}$ & $\mathrm{M}$ & 43 & In right musculus deltoideus & III \\
22 & $\mathrm{P}$ & $\mathrm{M}$ & 43 & In right musculus deltoideus & III \\
23 & $\mathrm{R}$ & $\mathrm{F}$ & 89 & Left elbow (intramuscular) & III \\
24 & $\mathrm{R}$ & $\mathrm{F}$ & 89 & Left elbow (intramuscular) & III \\
25 & $\mathrm{P}$ & $\mathrm{F}$ & 76 & In musculus sartorius & III \\
26 & $\mathrm{P}$ & $\mathrm{M}$ & 66 & Left thigh (invading the fascia) & III \\
27 & $\mathrm{R}$ & $\mathrm{F}$ & 71 & Whole arm (invading the bone) & III \\
28 & $\mathrm{P}$ & $\mathrm{M}$ & 68 & Left thigh (intramuscular) & III \\
29 & $\mathrm{M}$ & $\mathrm{M}$ & 69 & Right axillary lymph node & III \\
30 & $\mathrm{P}$ & $\mathrm{F}$ & 45 & Right upper arm (superficial) & III \\
31 & $\mathrm{R}$ & $\mathrm{F}$ & 64 & Left lower leg (superficial) & III \\
32 & $\mathrm{P}$ & $\mathrm{M}$ & 71 & Left lower arm (intramuscular) & III
\end{tabular}

\footnotetext{
${ }^{\mathrm{a}} \mathrm{P}=$ primary lesion; $\mathrm{R}=$ local recurrence; $\mathrm{M}=$ metastasis.
}

${ }^{\mathrm{b}} \mathrm{M}=$ male; $\mathrm{F}=$ female.
World Health Organization (WHO) criteria and histological grading was performed according to the FNLCC. ${ }^{2,5}$

\section{Cytogenetic Data}

Chromosomes were obtained using short-term cultures and harvesting procedures as described previously. ${ }^{6}$ Briefly, nonfixed tissue fragments were disaggregated mechanically and enzymatically and then cultured on chamber slides in DMEM-F12 medium (Gibco, Invitrogen, Breda, The Netherlands), supplemented with $10 \%$ fetal bovine serum and 0,5\% penicillin-streptomycin (Irvine Scientific, Santa Anna, CA, USA) for 4-9 days. For cases 1-17 and 19-29 the protocol was as follows. At $17 \mathrm{~h}$ before harvest, cells were exposed to Colcemid (0.005 $\mu \mathrm{g} /$ $\mathrm{ml}$; Gibco, Invitrogen, Breda, The Netherlands). After hypotonic treatment $(0.8 \%$ sodium citrate for $25 \mathrm{~min}$ ), the preparations were fixed three times with methanol-glacial acetic acid (3:1). Cytogenetic analysis was performed on GTG-banded chromosomes and the karyotypes were classified according to the International System for Human Cytogenetic Nomenclature. ${ }^{7}$

\section{Multicolor Fluorescence In Situ Hybridisation}

For cases 18, 30-32, cells were harvested, after which a 48-color fluorescence in situ hybridisation (FISH) staining was carried out, staining every chromosome-arm in a different colour combination, after which digital imaging and analysis was performed as previously described. ${ }^{8-10}$ Hybridisations with individual libraries labeled with single fluorochromes were used to confirm the detected rearrangements. Breakpoints were assigned by using inverted DAPI counterstained images of the chromosomes.

\section{Results}

\section{Patient Data}

The study of myxofibrosarcoma included eight grade I, eight grade II and 16 grade III cases. The morphological spectrum ranging from low- to highgrade morphology is depicted in Figure 1. Patient and tumour characteristics are depicted in Table 1, showing equal sex distribution between males and females with an average age of occurrence of 66 years. In all, 22 cases were primary lesions; nine of these lesions recurred locally and one was a lymph node metastasis. Of the six cases recurring as grade III lesions, the primary lesions were either grade III (four cases), grade II (one case) or grade I (one case). All three grade II recurrences were all primarily grade I. The metastasis was a grade III lesion. Except for this lymph node metastasis and one lesion occurring in the thoracic muscles (case 13), all 

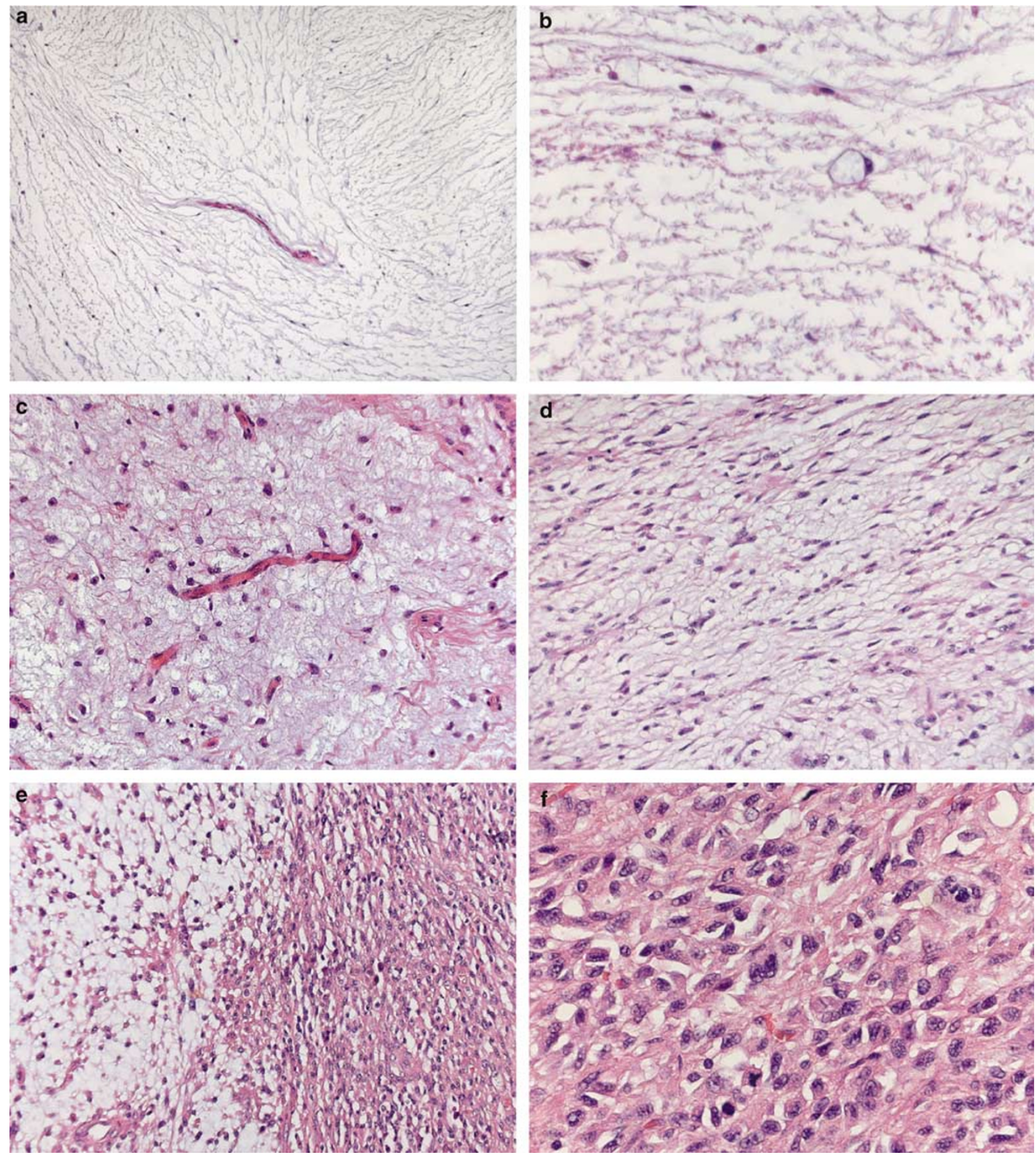

Figure 1 Light Micrographs displaying the morphological Spectrum of Myxofibrosarcoma. (a-c) Grade I myxofibrosarcoma showing a hypocellular lesion with typical elongated curvilinear blood vessels in a myxoid background with (pseudo)lipoblasts and slight nuclear atypia. (a) $\mathrm{HE} \times 10$; (b, c): $\mathrm{HE} \times$ 40. (d) Grade II myxofibrosarcoma showing a more cellular lesions with increased nucleair atypia. $\mathrm{HE} \times 20$. (e, f) Grade III myxofibrosarcoma consisting out of solid sheets of spindled, atypical cells and multinucleated giant cells with abundant eosinophillic cytoplasm. In the same tumour, there is often a remarkable but characteristic sharp transition between hypo-and hypercellular areas. (e) $\mathrm{HE} \times 20$; (f) $\mathrm{HE} \times 40$.

lesions occurred at the extremities (upper ones: 12; lower: 19). In all, 19 were deeply/intramuscular seated (case 13 included), 11 superficially with one not specified regarding the depth of the lesion (case 20).

\section{Cytogenetics}

The cytogenetics findings are listed in Table 2 showing normal to very complex karyotypes. None of them were published in previous publications 
Table 2 Cytogenetic analysis of the 32 myxofibrosarcomas

\begin{tabular}{|c|c|c|}
\hline Case & Grade & Karyotype \\
\hline 1 & I & 82-142,COMPLEX,+1-2M \\
\hline 2 & I & $46, \mathrm{XY} ; 45, \mathrm{XY},-22 / 46, \mathrm{XY}, \mathrm{t}(1 ; 10)(\mathrm{q} 22 ; \mathrm{p} 11)$ \\
\hline 3 & I & $46, \mathrm{XX} ; 45, \mathrm{XX},-21 / 92, \mathrm{XXXX} / 92, \mathrm{XXXX}$ \\
\hline 4 & I & $\begin{array}{l}\text { 46,XY; 43,Y,-X,-19,-20/45,X,-Y/46,XY,+dmin/47,XY,+X/46,XY,del(4)(Q22)/90,XXY,-Y,-12/91,XXYY,add(1)(P36), } \\
\operatorname{del}(2)(\mathrm{Q} 31),-10, \operatorname{add}(14)(\mathrm{P} 11),-16,-16,+\mathrm{M} \times 2\end{array}$ \\
\hline 5 & I & $46, \mathrm{XX}$ \\
\hline 6 & I & $46, \mathrm{XX}$ \\
\hline 7 & I & 46,XY,del(1)(p21-p31?),r(3)(q),del(5)(q),-13,del(15)(q13-26.3?) \\
\hline 8 & I & $46, \mathrm{XX}[25\}$ with random nonclonal aberrations \\
\hline 9 & II & 44-47,XX,NCA; 46,XX \\
\hline 10 & II & $46, \mathrm{XY} ; 47, \mathrm{XY},+\mathrm{M} ; 44, \mathrm{XY},-7,-21$ \\
\hline 11 & II & $82-82\langle N\rangle$, very complex with clonal aberrations \\
\hline $12^{*}$ & II & $70-77\langle N\rangle$,complex clonal aberrations \\
\hline 13 & II & 46,XY; 45,X,-Y/45,XY,-20/46,XY,t(2;7)(q37;q22)/46,XY,t(2;12)(q23;q12); 61-63〈3〉, complex and numerous chromosomal aberrations \\
\hline $14^{*}$ & II & $\begin{array}{l}\text { 72-85 }\langle\mathrm{N}\rangle, \mathrm{X}, \mathrm{X},+1, \text { add(1)(Q42),del(1)(Q32),2,del(2)(P23),add(3)(Q24), del(3)(P23P25), del(4)(Q22), del(5)(P13),+7,+8,DEL(8)(Q22)X2,+9, } \\
\text { add(9)(P24),add(10)(Q22),add(11)(P13),add(12)(P13),del(12)(P11),-13,add(13)(Q32),add(13)(Q31),14,add(14)(P13),add(16)(P13),del(16)(P11), } \\
\text { add(17)(Q25),+19,add(19)(Q13)X2,add(19)(P13),add(22)(P11),+9-14M(inc18); 46,XX }\end{array}$ \\
\hline $15^{*}$ & II & $46, \mathrm{XX} ; 45, \mathrm{XX},-21 / 46, \mathrm{XX}, \mathrm{inv}(12)(\mathrm{p} 11 \mathrm{q} 21)$ \\
\hline 16 & II & $46, \mathrm{XX} \quad 4$ \\
\hline 17 & III & $46, X Y$ \\
\hline 18 & III & 56-64〈3N $\rangle$, complex with clonal and nonclonal aberrations; 106-123 $\langle 6 \mathrm{~N}\rangle$,IDEMX2; 46,XX \\
\hline 19 & III & Polyploid,complex,+1-2M \\
\hline 20 & III & 46 XY, $-X, t(X ; 17)(p ; p), \operatorname{del}(3)(3 p), d e r 3(3 p t e r \rightarrow 3 q:: 8 q \rightarrow 8 q:: 9 q \rightarrow 9 q \operatorname{cter}), \operatorname{der} 8(8 p t e r \rightarrow 8 q:: 3 q \rightarrow 3 q$ ter),der9(9pter $\rightarrow 9 q:: 8 q \rightarrow 8 q t e r), t(11 ; 16)(q ; q)$ \\
\hline 21 * & III & $46, X Y ; 48, X Y,+7,+11$ \\
\hline 22 & III & $46, X Y$ \\
\hline $23^{*}$ & III & 46,XY; 44,XX, $-8,-17 / 45, \mathrm{X},-\mathrm{X} / 41, \mathrm{XX},-5,-8,-15,-22,-22 / 46, \mathrm{XX}, \mathrm{t}(4 ; 9)(\mathrm{q} 31 ; \mathrm{q} 34) / 82$, multiple and complex clonal aberrations \\
\hline $24^{*}$ & III & $46, \mathrm{XX}$, nonclonal aberrations; $80\langle 4 \mathrm{~N}\rangle$, nonclonal aberrations; 46,XX \\
\hline 25 & III & 58-109, complex clonal structural aberrations; 68-84, complex structural aberrations \\
\hline 26 & III & $\begin{array}{l}\text { Very abnormal karyotype with many clonal markers, for example, } 1 p-, 6 q+, 7 q+, 8 q+, 10 q+\text {, and extra copynumbers of CHR.1q, 6, 7, } 8 \text { 61-66,XXX,INC; } \\
46, X Y\end{array}$ \\
\hline $27^{*}$ & III & $46, \mathrm{XX} ; 2 \times-18,1 \times \mathrm{Xq}-$ \\
\hline 28 & III & $46, X Y$ \\
\hline 29 & III & $46, X Y$ \\
\hline 30 & III & $46, \mathrm{XX}$ \\
\hline $31^{*}$ & III & 45,XX,T(13;14)(Q10;Q10); near-triploid, few abnormal chromosomes, DMIN \\
\hline 32 & III & 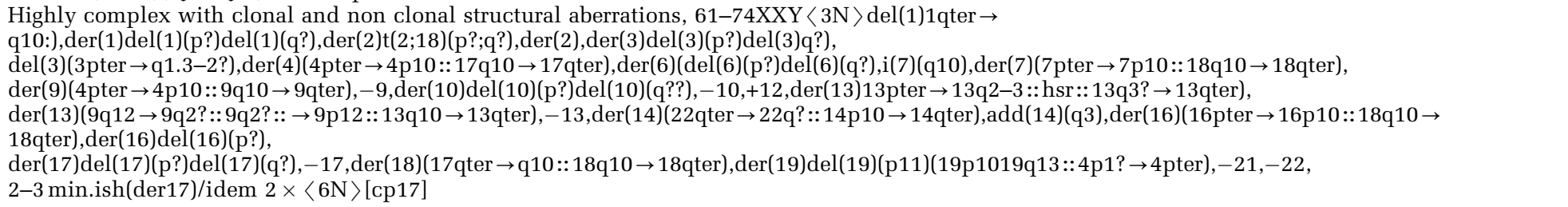 \\
\hline
\end{tabular}



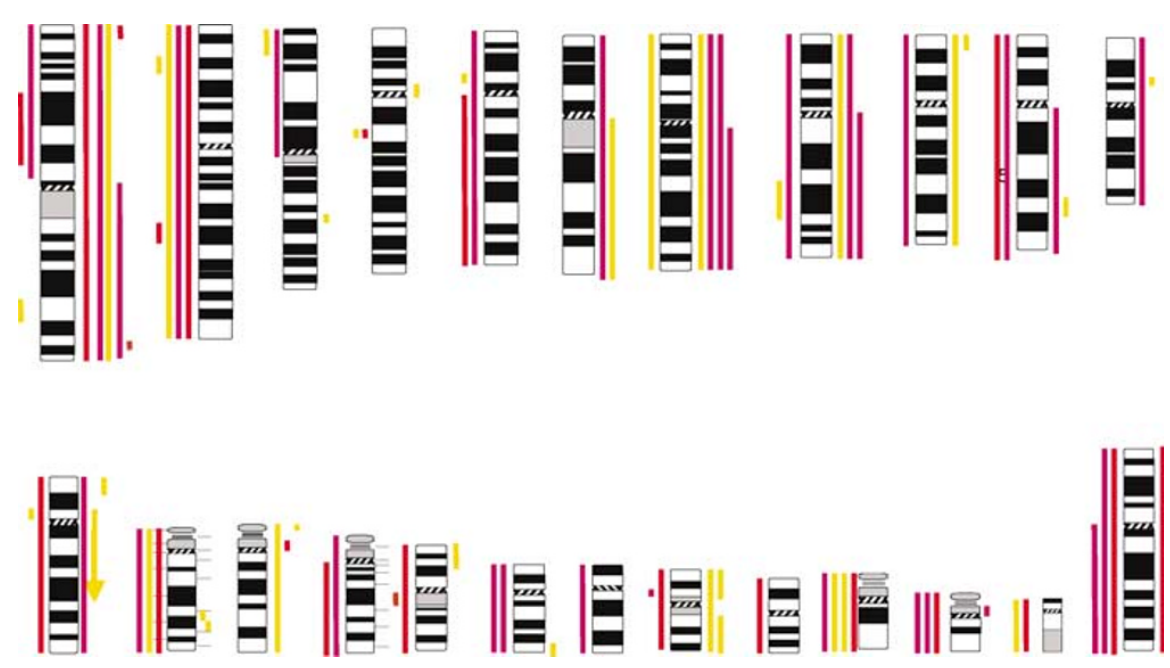

Figure 2 Karyotypic aberrations in 32 myxofibrosarcomas. Red=Grade I, Orange= Grade II, Purple= Grade III. Ideogram showing the distribution of the numerical and structural aberrations of 32 myxofibrosarcoma. Aberrations were found in all grades, including all chromosomes. No tumour or grade specific cytogenetic aberration could be withdrawn. Gains are shown on the right side of each chromosome diagram, losses on the left. Arrows indicate inversions.

including these entities by the authors. ${ }^{11}$ Eight normal karyotypes were found among these 32 myxofibrosarcoma. Clonal, besides nonclonal, aberrations were found in 22 cases. These aberrations were present in all grades. Complex cytogenetic anomalies were not restricted to grade III, but also seen in grade II and grade I cases. There was no difference in affected chromosomes depending on grade. Although some chromosomes were more involved than others (Figure 2), there were no consistent chromosomal abnormalities. In general, grade III lesions showed more complex karyotypes than lower grades. Remarkably, recurrences (indicated by asterisk) showed more complex karyotypes than both their grade II and grade III primary lesions. Furthermore, we found the presence of a ring chromosome, possibly originating from chromosome 3 (case 7).

\section{Discussion}

Myxofibrosarcoma is one of the most frequent sarcomas in elderly patients, mainly located on the extremities. ${ }^{2}$ Histologically, they compromise a continuous range from hypocellular tumours, consisting of small spindle cells widely spaced among the myxoid matrix, to more cellular variants with pleomorphic nuclei and pseudolipoblasts. ${ }^{1-4} \mathrm{~A}$ consistent morphologic feature is the presence of curvilinear blood vessels. Enzinger and Weiss ${ }^{3}$ classified the high-grade variant of these tumours as the myxoid variant of malignant fibrous histiocytoma, besides the storiform-pleomorphic, giant cell type and inflammatory subtypes. Angervall and Kindblom, ${ }^{1}$ almost simultaneously, first used the term myxofibrosarcoma, as they recognised this tumour as a distinct entity. Nowadays, the recogni- tion as a distinct, separate entity is generally accepted and included in the 2002 WHO classification of tumours. ${ }^{2}$ According to previous studies, grade II and III tumours are true malignant tumours since they have metastastic potential. This is in contrast to grade I lesions, which are only locally aggressive. ${ }^{4}$ However, since local recurrence goes together with increase in grade, grade I myxofibrosarcoma may finally gain metastatic potential, warranting close surveillance.

The differential diagnoses of myxofibrosarcoma include other myxoid tumours often hard to distinguish from each other, since differences are often very subtle. ${ }^{12}$ However, the distinction between all these myxoid subtypes is truly important from a clinical point of view, both for required therapy as for follow-up. Therefore, the existence of a specific (cyto) genetic aberration could serve as a welcome diagnostic marker and a helpful tool to distinguish these subtypes. However, cytogenetic data on myxofibrosarcoma are scarce, with only a few isolated cases described in literature showing complex, but nonspecific cytogenetic aberrations (Table 3). These include the presence of ring chromosomes, deletions and translocations. No specific chromosomal rearrangement has been identified so far.

Here, we investigated the clinicopathologic and cytogenetic data of 32 myxofibrosarcoma in order to find tumour and/or grade specific cytogenetic aberrations. Patient and tumour characteristics were in accordance to previous studies (Table 1). ${ }^{1-3}$ Although some authors suggested that deep-seated lesions were of higher grade, a large study of grade I myxofibrosarcoma could not confirm this, which is in accordance to our findings. ${ }^{4,25,26}$ Interestingly, the grade I tumours progressing to grade II were located superficially which shows that progression to recurrence is not exclusive for deep-seated lesions. 
Table 3 Karyotypes of the 30 Myxofibrosarcoma described in literature

Reference Karyotype

Clawson et $a l^{13}$ Johansson et al ${ }^{14}$

- 46,XX,t(2;15)(p23;q21),del(7)(q?11q?22)

Mandahl et $a l^{15}$

- 116-118,XXX,-Y,-Y,-1,-1, del(1)(q42),t(2;3)(p13;q11),-3,-5,-6,-6, dic(7;11)(q21;p13) × 2,-8,-9,-9, add(12)(p13), add(12)(q24), der(12)

$\mathrm{t}(1 ; 12)(\mathrm{p} 13 ; \mathrm{p} 11)$, add(13)(p11) $\times 2$,add(14)(q2?4),-15,-15, add(16)(q22-24),?der(17)t(17;18)(p12;q12) $\times 2,-18, \operatorname{add}(19)(\mathrm{p} 13), \operatorname{add}(22)(\mathrm{p} 11) \times 2, \operatorname{inc}$

- 44-46,X,-Y,add(19)(p13),inc/74-82,idem $\times 2$

- 76-80,XX, -X,+add(7)(q36) × 2,+der(7)del(7)(p13),add(7)(q32),+der(9)hsr(9)(p24)add(9)(p24) × 2,+add(11)(p11) × 2,der(12)t(1;12)(q23;p13) × 2, $\operatorname{add}(17)(\mathrm{p} 11) \times 2,+\operatorname{der}(19) \operatorname{add}(19)(\mathrm{p} 13) \operatorname{add}(19)(\mathrm{q} 13) \times 2,+6-12 \mathrm{mar}, \mathrm{inc} / 37-41, \mathrm{X},-\mathrm{X}$, inc

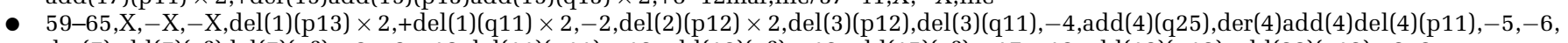
$\operatorname{der}(7) \operatorname{add}(7)(q ?) \operatorname{del}(7)(p ?),-8,-9,-10, \operatorname{del}(11)(p 11),-12$,add(12)(p?),-13,add(15)(q?),-17,-18,add(19)(p13), add(20)(q13),+3-8mar

- 46,XX,inv(3)(p25q13)/46,XX,del(1)(p12),der(3)del(3)(p25)ins(3;14)(q21;q32q23)t(3;3)(q29;p25)

$\mathrm{t}(1 ; 3)(\mathrm{p} 12 ; \mathrm{p} 26), \operatorname{del}(14)(\mathrm{q} 23) / 44-45, \mathrm{X},-X$, add(3)(p25), der(3)add(3)(p25)add(3)(q13),+7, +7, add(9)(p24), add(9)(q34),-10,-12,-13,+add(14)(p11), $+18,-19,+\operatorname{add}(20)(\mathrm{q} 13),-21,-21,-22,-22,+1-2 \mathrm{r},+1-3 \mathrm{mar}$

- 65-69,X,-X, -X,+del(1)(q11),+del(1)(q12),del(2)(q31),+del(3)(p12), add(4)(p16),add(4)(p11),+6,+der(7),inv(7)add(7)(q36),+inv(7)(p15q11),del(8)(q?), $\operatorname{del}(9)(q 11), \operatorname{add}(11)(q 25), \operatorname{del}(11)(\mathrm{p} 11),+\operatorname{der}(11) \operatorname{add}(11), \operatorname{del}(11)(\mathrm{p} 15), \operatorname{add}(13)(\mathrm{q} ?),+14,+14,+15, \operatorname{add}(16)(\mathrm{q} 23), \operatorname{del}(17)(\mathrm{p} 11),+18,+19,+21, \operatorname{add}(22)(\mathrm{q} 13),+3-7 \mathrm{mar}$

Meis-Kindblom et al ${ }^{16} \bullet 44-46, \mathrm{XX},-16$

Meloni-Ehrig et $a l^{17} \bullet 47, \mathrm{XX},+\mathrm{r}(20)(\mathrm{q} ?) / 48, \mathrm{idem},+\mathrm{r}$

Mertens et $a l^{11}$

- 55-60,XXY,+Y,-1,-2,-3,-4,add(4)(p16),add(5)(p15),der(5)t(4;5)(q12;p11-

13), $-6,+7,-9,-10, \operatorname{del}(10)(\mathrm{q} 24),-13, \operatorname{der}(14) \mathrm{t}(9 ; 14)(\mathrm{q} 13 ; \mathrm{p} 11),-16,-17,-18,-19,-21,-22,+\mathrm{mar}, 2-30 \mathrm{dmin}$

- 43-44,XY,-2,-5, add(7)(q32),add(8)(p11), -9 , add(13)(p11),i(14)(q10),-17,-18,-20,inc/81-84,idem $\times 2$, add(12)(p11) $\times 2$

- 80-85,XXXX,del(1)(q12),add(6)(q15),add(11)(p15),add(12)(q22),add(18)(p11),inc41,XX,del(1),add(6),add(11),add(12),inc

- 66-73,XXX,add(1)(p32),der(1)add(1)(p36)del(1)(q12),der(3)add(3)(p13)add(3)(q27),der(3)del(3)(p11) add(3)(q27),add(6)(p24),del(7)(p12),del(7)(q32),add(8)(p11) × 2,der(9)del(9)(p21)add(9)(q34) × 2,del(10)(p11),der(11)t(11;15)(p11;q12),add(12)(p11), $\operatorname{add}(14)(\mathrm{q} 32), \operatorname{add}(16)(\mathrm{q} 12), \operatorname{add}(19)(\mathrm{p} 12), \operatorname{der}(20)$ $\mathrm{t}(8 ; 20)(\mathrm{q} 13 ; \mathrm{q} 13), \operatorname{der}(20) \mathrm{t}(17 ; 20)(\mathrm{q} 21 ; \mathrm{q} 13), \operatorname{add}(21)(\mathrm{q} 22), \operatorname{add}(22)(\mathrm{p} 12)$, inc

- 76-81,XX,-Y,add(2)(q37),del(4)(p15),del(11)(p11),der(11;16)(q10;q10),del(12)(p12),add(19)(p13),inc

- 37-44,XY,del(1)(p11),add(5)(p15),del(5)(p14),der(10;12)(q10;q10),der(15)t(11;15)(q13;p11),add(19)(p11),inc/67-69,idem $\times 2$

- 37-40,X,-X,-1, add(1)(q21),-2,der(2)t(1;2)(q21;p2?5), add(3)(q13),-4,-5, add(6)(q15),add(6)(q27), -8,add(8)(p11),add(10)(p11), $\operatorname{add}(10)(p 15),-11, i(11)(q 10),-13, \operatorname{add}(13)(q 34),-14,-14, \operatorname{add}(15)(p 11), \operatorname{add}(19)(p 11), \operatorname{add}(19)(q 13),-22,+r, i n c / 74-78, i d e m \times 2$

Mertens et $a 1^{18}$

- 66-78,XY,-X,del(1)(q11),del(1)(q21),add(2)(q37), del(5)(p13),add(12)(p11),inc

- 46,XX,del(2)(q23q31),der(3)del(3)(p21)add(3)(q23),del(4)(q31),t(6;14)(p11;q11),der(7)t(3;7)(q23;q22) $\operatorname{ins}(7 ; ?)(q 22 ; ?), \operatorname{der}(13) t(4 ; 13)(q 31 ; q 32),+\operatorname{der}(?), t(? ; 21)(? ; q 11) /$ 46,XX,der(1)t(1;6)(p34;p25)add(1)(q12), add(3)(q12),der(6)t(1;6)(p34;p25), der(20),t(1;20)(q25;p13)/46,XX,add(9)(q34),del(13)(q12q21), $\operatorname{add}(21)(q 22) / 46, t(X ; 16)(p 22 ; q 13), t(X ; 17)(p 11 ; q 23) / 43-47, X,-X,+r, i n c / 47, X,-X, \operatorname{der}(1) t(1 ; 10)(p 12 ; q 11), \operatorname{der}(1) \operatorname{del}(1)(p 32) \operatorname{dup}(1)(p 32 p 11),-4,+7$, $\operatorname{add}(10)(\mathrm{q} 11), \operatorname{der}(17) \mathrm{t}(4 ; 17)(\mathrm{q} 21 ; \mathrm{q} 23),+2 \mathrm{mar}$

Nilsson et al ${ }^{19}$

- 42,XY,dic(1;?)(p11;?),-2,der(3)t(3;?7)(p12;q21),-9,-10,add(12)(p11),add(13)(p11),add(14)(q32),?der(16)add(16)(p11)del(16)(q22) add(17)(p11),add(21)(p11),-22,-22

- 39-48,-X,-Y,del(6)(q15),-10,add(11)(p15),+r(12) × 1-2,inc,40-48,X,-Y,del(6), $-9,-10,-? 11,-15,+\operatorname{der}(?) \mathrm{r}(? ; 12) \times 2$, inc

- 49-50,X, $-X,+1,+\operatorname{der}(1 ; 14)(p 10 ; q 10), \operatorname{der}(1) a d d(1)(p 22) \operatorname{add}(1)(q 32) \times 2,+5$, add(5) (p15) $\times 2,+12$, ?del(16)(q22),?dup(17)(q21q25), $-18,+19,+22,+\operatorname{mar}$

- 32-35,X,-X,-1,del(2)(p11),-3,der(7;15)(q10;q10),-8, add(9)(p11),-10,-11,del(11)(p11),-13,add(14)(p11),add(16)(q13),-17,-18,-19,-20,-21,-22, inc/62-68,idem $\times 2$,add(13)(p13)

Simons et $a l^{20}$

- $\quad 85-87, X$ ?,del(1)(q42),add
$\operatorname{add}(19)(\mathrm{q} 13) \times 1-3$, inc

- 68-75,XX,add(X)(p22), del(1)(p13),del(1)(p33),der(1)t(1;5)(q21;q13) × 2,del(2)(p14),-3,-3,del(3)(q21),-4,-4, add(4)(p15), $-5,-5, \operatorname{del}(6)(q 21),+7,-9, \operatorname{add}(9)(p 22), \operatorname{del}(9)(p 13),-10,-10, \operatorname{add}(11)(q 23), \operatorname{del}(17)(p 13), \operatorname{add}(19)(q 13) \times 2,+\operatorname{del}(20)(q 13)$, add(22)(p13),+4-11mar

Szymanska et $a^{21}$

- 58-71,XX?,+4mar,20-23dmin,inc

Örndal et $a l^{22}$

- 46,XX,add(1)(q21) or add(1)(q32),t(1;10)(p22;q22),tas(5;5)(q35;q35),tas(10;?)(q26;?),+14,tas(18;?)(q23;?)/46,XX,add(21)(p11)

46-51,X, $-\mathrm{Y},-22,+2-7 \mathrm{r} / 45-50$, idem, -18 
Normal karyotypes were seen in eight cases (five grade III, two grade II and one grade I lesion). Aberrations occurred in all chromosomes; no consistent tumour-specific cytogenetic rearrangement was identified. Those cases with cytogenetic abnormalities were not restricted to a certain grade with grade I, II and III lesions showing a wide range from normal till very complex, polyploid karyotypes (Figures 2,4). Grade III tumours had, overall, more complex karyotypes than grade I and grade II lesions. This suggests that these complex karyotypic abnormalities occur rather randomly as secondary events. We showed that local recurrences occurred in all grades, with increase in grade upon recurrence, which is in accordance to the literature. ${ }^{2,27}$ We hypothesised that in the same lesion, increase in grade goes together with increase in cytogenetic aberrations. Therefore, we compared the karyotypes of primary lesions to these of the corresponding local recurrences. Recurrences showed increase in grade and more complex aberrations than the primary tumours (Figure 3). These complex aberrations suggest additional chromosomal events, corresponding with an increase in histological grade and, subsequently, increase in malignant potential.

Besides nonclonal and clonal aberrations, we found the presence of a ring chromosome in one case of low-grade myxofibrosarcoma. The presence of ring chromosomes has also have been described in one case of myxofibrosarcoma possibly originating from 20q. ${ }^{17}$ Ring chromosomes have been described in many tumours, both benign as well as malignant, including dedifferentiated liposarcoma, a differential diagnosis of grade III myxofibrosarcoma. ${ }^{11,28}$ However, this is certainly not a consistent feature and its molecular and biological significance has not been revealed yet. Previous reports described several translocations in myxofibrosarcoma. Although all of them were different and nonspecific, some of these involve interesting regions. For example, Clawson et $a l^{13}$ described a case of grade I myxofibrosarcoma with translocation $\mathrm{t}(2 ; 15)$ (p23;q21.2). The band $2 \mathrm{p} 23$ is a site of $A L K$ gene, expressed in normal tissue and rearrangements have been described in anaplastic large cell lymphomas, and inflammatory myofibroblastic tumours. ${ }^{29,30}$ Translocations involving $2 \mathrm{p} 23$ have been found in a case of synovial sarcoma as $t(2 ; 15)(p 23 ; q 26)$ and also in one case of 'malignant fibrous histiocytomas not otherwise specified' as $\mathrm{t}(2 ; 5)(\mathrm{p} 23 ; \mathrm{q} 13) .^{31,32}$ Frequent loss of 9p21 (p16) has been reported in malignant fibrous histiocytomas including also some cases of myxofibrosarcoma. ${ }^{20,33,34}$ We could not confirm these aberrations in our study. Some studies showed add2(q37) in myxofibrosarcoma and in several types of leukaemia. ${ }^{11}$ Interestingly, the COL6A1 gene is localised to $2 q 37$, coding for collagen VI alpha-3 polypeptide. At least three other extra cellular matrix genes are also located on 2q: 2 collagen genes, COL3A1 and COL5A2 and the fibronectin gene. ${ }^{35}$ As described above, myxofibrosarcoma 


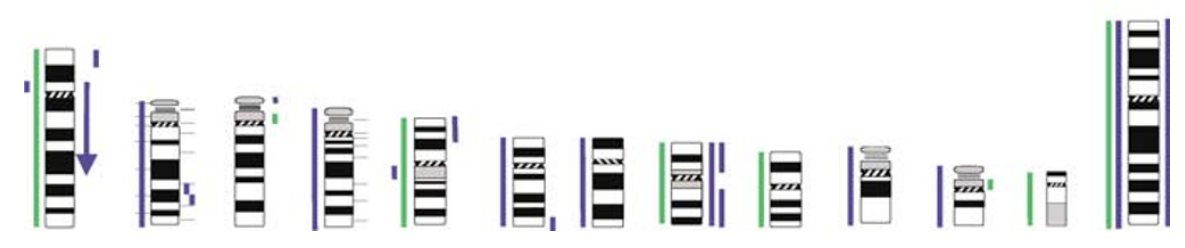

Figure 3 Karyotypic aberrations in nine myxofibrosarcomas comparing primary lesions to their recurrences. Blue: Primary tumour, Red: Recurrence. Ideogram showing the distribution of the numerical and structural aberrations of primary tumours compared to their local recurrences. Recurrences show more complex cytogenetic aberrations than the primary tumours. Gains are shown on the right side of each chromosome diagram, losses on the left. Arrows indicate inversions. In general, there is gain of cytogenetic aberrations with recurrence though no specific pattern is observed for this phenomenon.

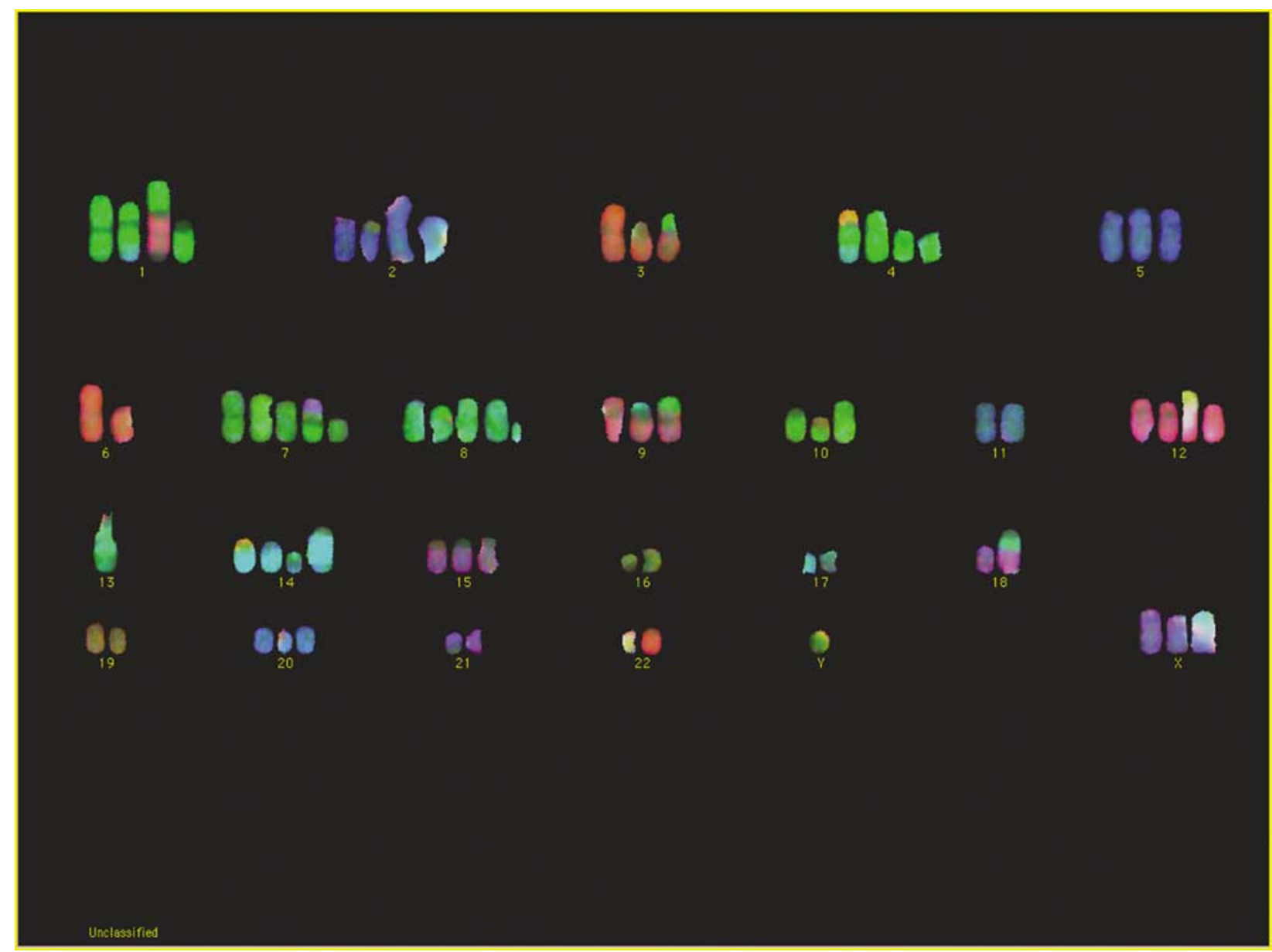

Figure 4 COBRA-FISH in a case of a high-grade myxofibrosarcoma. Example of highly complex cytogenetic aberrations in a case of highgrade myxofibrosarcoma (case 32). For karyotypic aberrations see Table 2.

contains areas of abundant extracellular matrix although only little is known about its constitution. Ultrastructural studies showed that the majority of cells in myxoid areas of myxofibrosarcoma showed secretory activity with dilated rough endoplasmatic reticulum. Although further study is needed, alterations in 
genes coding for matrix proteins might lead to increased or impaired matrix production. Interestingly, a myxofibrosarcoma-like appearance appears to be quite frequent in pleomorphic liposarcoma, thereby including it in the differential diagnosis. ${ }^{36}$ In the light of this differential diagnosis, the cases reported here were carefully characterised, explicitly excluding contaminations with pleomorphic liposarcoma karyotypes in this series of myxofibrosarcoma. Finally, a recent study using comparative genomic hybridisation (CGH) showed very similar chromosome imbalances between myxoid malignant fibrous histiocytoma and pleomorphic liposarcoma, suggesting partially common genetics and biology. ${ }^{37}$ This study showed gain of $5 p$ and loss of $4 q$ in myxofibrosarcoma of higher grade compared to tumours of lower grade. Whether these and other myxoid soft tissue tumours, in parallel to their morphologic resemblance, also share genetic overlap is a very interesting hypothesis, which, however, still needs to be confirmed.

\section{Acknowledgements}

We thank M Yszenga for performing the COBRAFISH experiments. This project was financially supported by a Grant (RUL 2001-2526) from the Dutch Cancer Foundation. This text presents research results of the Belgian program on Interuniversity Poles of Attraction initiated by the Belgian Sate, Prime Minister's Office, Science Policy Programming. Its authors assume the scientific responsibility. The authors would like to acknowledge the COST support through the COST ACTION B19 'Molecular cytogenetics of solid tumors' in carrying out this work.

\section{References}

1 Angervall L, Kindblom LG, Merck C. Myxofibrosarcoma. A study of 30 cases. Acta Pathol Microbiol Scand [A] 1977;85A:127-140.

2 Mentzel T, Van den Berg E, Molenaar WM. Myxofibrosarcoma. In: Fletcher CDM, Unni KK, Mertens F (eds). World Health Organization classification of tumours. pathology and genetics. Tumours of soft tissue and bone, 2002 edn. IARC press: Lyon, 2004, pp 102-103.

3 Weiss SW, Enzinger FM. Myxoid vaiant of malignant fibrous histiocytoma. Cancer 1977;39:1672-1685.

4 Mentzel T, Calonje E, Wadden C, et al. Myxofibrosarcoma. Clinicopathologic analysis of 75 cases with emphasis on the low-grade variant. Am J Surg Pathol 1996;20:391-405.

5 Trojani M, Contesso G, Coindre JM, et al. Soft-tissue sarcomas of adults; study of pathological prognostic variables and definition of a histopathological grading system. Int J Cancer 1984;33:37-42.

6 Limon J, Dal Cin P, Sandberg AA. Application of longterm collagenase disaggregation for the cytogenetic analysis of human solid tumors. Cancer Genet Cytogenet 1986;23:305-313.

7 ISCN. An international system for human cytogenetic nomenclature. S.Karger: Basel, 1995.

8 Szuhai K, Knijnenburg J, Ijszenga M, et al. Multicolor fluorescence in situ hybridization analysis of a synovial sarcoma of the larynx with a $t(X ; 18)(p 11.2 ; q 11.2)$ and trisomies 2 and 8. Cancer Genet Cytogenet 2004; 153:48-52.

9 Tanke HJ, Wiegant J, Van Gijlswijk RPM, et al. New strategy for multi-colour fluorescence in situ hybrydisation: COBRA: COmbined Binary RAtio labelling. Eur J Hum Genet 1999;7:2-11.

10 Wiegant J, Bezrookove V, Rosenberg C, et al. Differentially painting human chromosome arms with combined binary ratio-labeling fluorescence in situ hybridization. Genome Res 2000;10:861-865.

11 Mertens F, Fletcher CD, Dal Cin P, et al. Cytogenetic analysis of 46 pleomorphic soft tissue sarcomas and correlation with morphologic and clinical features: a report of the CHAMP Study Group. Chromosomes and MorPhology. Genes Chromosomes Cancer 1998;22: 16-25.

12 Graadt van Roggen JF, Hogendoorn PCW, Fletcher CDM. Myxoid tumours of soft tissue. Histopathology 1999;35:291-312.

13 Clawson K, Donner LR, Dobin SM. Translocation $(2 ; 15)(\mathrm{p} 23 ; \mathrm{q} 21.2)$ and interstitial deletion of $7 \mathrm{q}$ in a case of low-grade myxofibrosarcoma. Cancer Genet Cytogenet 2001;127:140-142.

14 Johansson M, Karauzum SB, Dietrich C, et al. Karyotypic abnormalities in adenocarcinomas of the lung. Int J Oncol 1994;5:17-26.

15 Mandahl N, Heim S, Willén $\mathrm{H}$, et al. Characteristic karyotypic anomalies identify subtypes of malignant fibrous histiocytoma. Genes Chromosomes Cancer 1989;1:9-14.

16 Meis-Kindblom JM, Sjogren H, Kindblom LG, et al. Cytogenetic and molecular analyses of liposarcoma and its soft tissue simulators: recognition of new variants of differential diagnosis. Virchows Arch 2001; 439:141-151.

17 Meloni-Ehrig AM, Chen Z, Guan XY, et al. Identification of a ring chromosome in a myxoid malignant fibrous histiocytoma with chromosome microdissection and fluorescence in situ hybridization. Cancer Genet Cytogenet 1999;109:81-85.

18 Mertens F, Larramendy M, Gustavsson A, et al. Radiation-associated sarcomas are characterized by complex karyotypes with frequent rearrangements of chromosome arm 3p. Cancer Genet Cytogenet 2000; 116:89-96.

19 Nilsson M, Meza-Zepeda LA, Mertens F, et al. Amplification of chromosome 1 sequences in lipomatous tumors and other sarcomas. Int J Cancer 2004; 109:363-369.

20 Simons A, Schepens M, Jeuken J, et al. Frequent loss of 9p21 (p16(INK4A)) and other genomic imbalances in human malignant fibrous histiocytoma. Cancer Genet Cytogenet 2000;118:89-98.

21 Szymanska J, Tarkkanen M, Wiklund T, et al. A cytogenetic study of malignant fibrous histiocytoma. Cancer Genet Cytogenet 1995;85:91-96.

22 Orndal C, Mandahl N, Rydholm A, et al. Supernumerary ring chromosomes in 5 bone and soft-tissue tumors of low Or borderline malignancy. Cancer Genet Cytogenet 1992;60:170-175. 
23 Orndal C, Mandahl N, Willen H, et al. Cytogenetic evolution in primary tumors, local recurrences, and pulmonary metastases of 2 soft-tissue sarcomas. Clin Exp Metast 1993;11:401-408.

24 Orndal C, Rydholm A, Willen H, et al. Cytogenetic intratumor heterogeneity in soft-tissue tumors. Cancer Genet Cytogenet 1994;78:127-137.

25 Huang HY, Lal P, Qin J, et al. Low-grade myxofibrosarcoma: a clinicopathologic analysis of 49 cases treated at a single institution with simultaneous assessment of the efficacy of 3-tier and 4-tier grading systems. Hum Pathol 2004;35:612-621.

26 Merck C, Angervall L, Kindblom LG, et al. Myxofibrosarcoma. A malignant soft tissue tumor of fibroblastichistiocytic origin. A clinicopathologic and prognostic study of 110 cases using multivariate analysis. Acta Pathol Microbiol Immunol Scand Suppl 1983;282: $1-40$.

27 Ferguson PC, Deshmukh N, Abudu A, et al. Change in histological grade in locally recurrent soft tissue sarcomas. Eur J Cancer 2004;40:2237-2242.

28 Dei Tos AP, Doglioni C, Piccinin S, et al. Coordinated expression and amplification of the MDM2, CDK4, and HMGI-C genes in atypical lipomatous tumours. J Pathol 2000;190:531-536.

29 Lawrence B, Perez-Atayde A, Hibbard MK, et al. TPM3-ALK and TPM4-ALK oncogenes in inflammatory myofibroblastic tumors. Am J Pathol 2000;157: 377-384.
30 Mitelman F, Mertens F, Johansson B. A breakpoint map of recurrent chromosomal rearrangements in human neoplasia. Nat Genet 1997;15(Spec No):417-474.

31 Mandahl N, Heim S, Arheden K, et al. Multiple karyotypic rearrangements, including $t(X ; 18)(p 11 ; q 11)$, in a fibrosarcoma. Cancer Genet Cytogenet 1988;30:323-327.

32 Mandahl N, Heim S, Arheden K, et al. Separate karyotypic features in a local recurrence and a metastasis of a fibrosarcoma. Cancer Genet Cytogenet 1989;37:139-140.

33 Weng WH, Ahlen J, Lui WO, et al. Gain of $17 \mathrm{q}$ in malignant fibrous histiocytoma is associated with a longer disease-free survival and a low risk of developing distant metastasis. Br J Cancer 2003;89:720-726.

34 Martignetti JA, Gelb BD, Pierce H, et al. Malignant fibrous histiocytoma: inherited and sporadic forms have loss of heterozygosity at chromosome bands 9p21-22-evidence for a common genetic defect. Genes Chromosomes Cancer 2000;27:191-195.

35 Weil D, Mattei MG, Passage E, et al. Cloning and chromosomal localization of human genes encoding the three chains of type VI collagen. Am J Hum Genet 1988;42:435-445.

36 Hornick JL, Bosenberg MW, Mentzel T, et al. Pleomorphic liposarcoma: clinicopathologic analysis of 57 cases. Am J Surg Pathol 2004;28:1257-1267.

37 Idbaih A, Coindre JM, Derre J, et al. Myxoid malignant fibrous histiocytoma and pleomorphic liposarcoma share very similar genomic imbalances. Lab Invest 2005;85:176-181. 